\title{
PREFACE
}

Great honor to organize the first edition of the International Conference on Energy and Green Computing (ICEGC'2021) and provide an academic exchange platform to share the latest researches, developments, advances and new technologies in the fields of Energy Engineering, Engineering Technologies, Renewable Energy, IT Energy-aware Technologies, Green ICT Systems and Green Computing. The participants had the opportunity to be in tune with the latest trends in research related to the themes of the conference, which was a meeting space to disseminate novel ideas and emerging trends, research results and practical achievements.

Due to the Covid-19 pandemic and the travel restrictions, ICEGC'2021 was taken place in hybrid mode on December 09-10, 2021 at Faculty of Sciences Meknes, Morocco. The conference mainly conducted in the forms of keynote speech, oral presentations, fruitful debates and discussions. 203 papers were submitted to ICEGC'2021 conference. Each paper has been evaluated by 3 to 5 reviewers, 79 papers were selected and accepted finally in ICEGC'2021 Proceedings.

Many people have collaborated and worked hard to produce a successful ICEGC'2021 conference. Thus, we would like to thank all the authors for their interest to this conference, the Scientific Committee members, who carried out the most difficult work by carefully evaluating the submitted papers, with professional reviewing and prompt response. Thanks to Session Chairs Committee for their efforts in making this conference a success. Our special thanks to our distinguished Keynote Speakers.

Finally, we would also like to express our gratitude to Organizing Committee who work very hard to ensure high standards and quality of keynotes, panels, presentations and discussions.

\section{ICEGC'2021 Organization Committees}

BENHALA Bachir Faculty of Sciences Meknes, Morocco

MANSOURI Khalifa ENSET Mohammedia, Morocco

RAIHANI Abdelhadi ENSET Mohammedia, Morocco

QBADOU Mohammed ENSET Mohammedia, Morocco 